UNIVERSITY OF WASHINGTON

DEPARTMENT OF OCEANOGRAPHY

Seattle, Washington 98105

Technical Reports

Nos. 136, 137, 138, 139, 140, and 141

A COMPIIATION OF ARTICLES REPORTING

RESEARCH SPONSORED BY

THE OFFICE OF NAVAL RESEARCH

Office of Naval Research

Reference M66-1

Contracts Nonr-477(10)

January 1966 and Nonr-477(37)

Project NR 083012

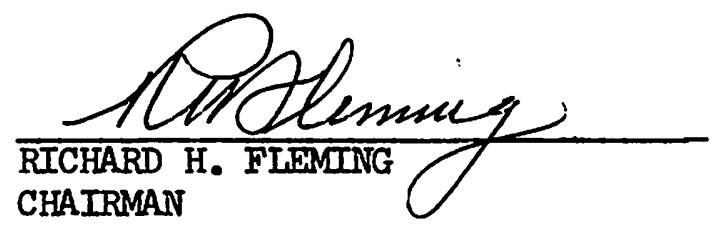

Reproduction in whole or in part is permitted for any purpose of the United States Government 
ON THE VERTICAL DISTRIBUTION OF ZOOPIANKTON IN THE SEA, by K. Banse. Pp. 55-125 in Progress in Oceanography, vol. II (Mary Sears, ed.). Pergamon Press, Iondon. 1964.

Technical Report No. 137

SYNONYMS OF PROTODORVILIEA EGENA (EHIERS) (EUNICIDAE, POLYCHAETA), bY K. Banse and G. Hartmann-Schröder. Proceedings of the Biological society of Washington, 77:241-242. 30 December 1964.

Technical Report No. 138

THE INFLUENCE OF VARIABLE DEPTH ON STEADY ZONAL BAROTROPIC FLOW, by Gene H. Porter and Maurice Rattray, Jr. Deutsche Hydrographische Zeitschrift, $17(4): 164-174$. 1964 .

Technical Report No. 139

THE MESOPEIAGIC CARIDEAN SHRTMP NOTOSTOMUS JAPONICUS BATE IN THE NORTHEASTERN PACIFIC, by Belle A. Stevens and Fenner A. Chace, Jr. Crustaceana, 8(pt. 3):277-284. 1965.

Technical Report No. 140

CARBONIFEROUS GIACIAL ROCKS FROM THE WERRIE BASIN, NEW SOUTH WALES, AUSTRAITA, by John T. Whetten. Geological Society of America Bulletin, 76:43-56. January 1965.

Technical Report No. 141

THE ORIGIN OF MANGANESE NODULES ON THE OCEAN FLOOR, by Enrico Bonatti and Y. Rammohanroy Nayudu. American Journal of Science, 263:17-39. January 1965. 


\title{
The Influence of Variable Depth on Steady Zonal Barotropic Flow*
}

\author{
By Gene H. Porter** and Maurice Rattray, Jr.
}

Summary. Solutions are obtained in frictionless, steady barotropic flow for the effect of simple bathymetric features on an initially uniform zonal current. For flow towards the west; an infinitely long ridge or valley causes an infinite streamline deflection while for flow towards the east, either an infinite deflection or a stationary Ross by wave pattern may occur. Several examples are given which illustrate the behavior of these waves.

* Contribution No. 319 from the Department of Oceanography, University of Washington. This investigation was supported in part by the Office of Naval Research under Contract Nonr477(10), Project NR 083012 and in part by the National Science Foundation, Grant GP-1101.

** This research was performed while the senior author was on active duty with the United States Navy as a participant in the Junior Line Officers Advanced Scientific Education Program (Burke Program). 
Der Einfiuß éinfacher Bodentopographie aů eine stetige, zonale und barotropische Strömung (Zusammenfassung). Lösungen für Gleichungen werden gegeben, welche die Wirkung einfacher Bodentopographie auf eine anfangs uniforme zonale Strömung beschreiben, die reibungslos, stetig und barotropisch ist. Fin unendlich langer Rücken oder ein unendlich langes Tal verursachen bei Strom nach Westen eine unendliche Ablenkung der Stromlinien, während bei Strom nach Osten ent: weder eine unendliche Ablenkung oder ein stationäres Rossby-Wellenmuster auftreten können. Mehrere Beispiele werden für das Verbalten dieser Wellen gegeben.

L'effet de simples topographies sur un courant zonal, continuel et barotropique (Résumé). Des solutions sont obtenues pour l'effet de simples topographies sur un courant zonal (uniforme a l'état initial) dans une mer homogène sans frottement (pour un mouvement permanent). Dans le cas de mouvement vers l'Ouest, un banc infiniment long (chaîne de montagnes) ou une vallée sous-marine donne naissance à une déflection infinie des lignes de courant; dans le cas de mouvement vers l'Est une déflection infinie ou une configuration stationnaire de vagues de Rossby peuvent être présent. Plusieurs examples sont donnés afin d'illustrer la nature de ces configurations.

Tntroduction. In most studies of the large scale circulation of the oceans, the sea floor is assumed to be either flat or infinitely deep, or consideration is restricted to an upper layer overlying a motionless lower layer. The results of such treatments, of course, cannot be expected to show any of the features of the flow in the real ocean that are associated with underlying bathymetry.

That such bathymetric effects do exist has been widely recognized. The classic example is that of the Antarctic Circumpolar Current in its passage over each of several ridges. Other examples that have been noted include, for example, the deflection of both the North Atlantic Current and the North Equatorial Current by the Mid-Atlantic Ridge, and the southerly excursion of the Gulf Stream as it passes over the Southeast Newfoundland Ridge.

Early treatments of topographic effects either linearized the problem by considering only small changes in depth and small bottom slopes (V. W. Ekman [1923,1932]; H. Görtler [1941]) or obtained only the qualitative effects of bottom features on the internal solenoidal field (H. U. Sverdrup [1941]). V. B. Shtokman [1948] extended these linearized models to include wind stress, whereas G. Neumann [1960] also considered a variable Coriolis parameter, inhomogeneity, and internal friction.

The linear treatment of the problem (i.e., the neglect of the inertial accelerations) implies that the ratio of relative vorticity to planetary vorticity (Rossby Number) is small compared to unity. It is clear that in low latitudes such a requirement is not always satisfied. In addition, K. Gambo [1957] has shown that it is not necessarily satisfied at higher latitudes when the flow is over slopes steeper than about $10^{-3}$. This is certainly less slope, by an order of magnitude or more, than is frequently found for both sub-aerial and submarine topographies. M. Oi [1956] was able to include inertial terms by neglecting the disturbance of the meridional pressure gradient for zonal flow over a bottom feature, but he did not include a variable Coriolis parameter. Görtler [1941] pointed out, as did Ekman [1932], that topographic effects in which inertia plays an important role may not be properly treated as independent of planetary effects for large scale motion.

In an important contribution to the understanding of the Gulf Stream, B. Warren [1963] included nonlinearity in his beta-plane investigation of the characteristically meandering Stream after it departs the continental shelf and flows obliquely over the continental slope. He was able to show that the observed meanders in the Stream can be explained by the bathymetry, and that it is not necessary to assume instabilities in the mean flow. Although. the northwestern Atlantic must be considered one of the most intensively studied oceanic areas in the world, the observational basis of Warren's study is still tenuous. Of key importance is the presumption of a non-reversing Gulf Stream velocity profile that extends to the bottom throughout its course. Warren inferred such a profile from the results of the 1960 Gulf Stream survey. More recent evidence (Fuglister [1963]) suggests the existence of an appreciable counter-current beneath the Stream in the vicinity. of $35^{\circ} \mathrm{N}-75^{\circ} \mathrm{W}$, the region considered by Warren as the origin of the meandering Stream, although nearly $1000 \mathrm{~km}$ southwest of the region of large scale meandering. 
It should be noted that almost all of the observations of topographic effects on ocean currents have been inferred from the distribution of properties. On the other hand, attempts to treat the problem theoretically have been primarily directed towards the barotropic model. The latter approach is followed in the succeeding analysis, and it is therefore not expected that solutions for this barotropic flow over bottom features of a realistic scale will correspond directly to observations of the baroclinic model. Indeed, the degree of correspondence between the theory and observation may be considered to represent a measure of the coupling between the bathymetry and the baroclinic model. Herein apparently lies the reason for the qualitative success of the earlier linearized perturbation models; i.e., considerably smaller features than those existing in the real ocean are sufficient to produce effects in a barotropic model that are comparable in amplitude to those observed in the baroclinic model.

In the following analysis, Görtler's [1941] conclusion that friction exerts only a minor influence compared to bathymetric effects in barotropic flow is accepted and friction is neglected, although it is recognized that friction must be important in some limiting sense. The solution obtained for an initially uniform zonal flow over a zonally variable depth clearly demonstrates the mechanism of the generation of stationary Ross by waves whose amplitude may become very large, even over a downstream region of uniform depth.

The vorticity equation for a frictionless homogeneous ocean. We define $u, v$, and $w$ as the velocity components along the $x$ (eastward), $y$ (poleward), and $z$ (upward) axes, respectively,

$f$ as the Coriolis parameter,

$p$ as the pressure,

$g$ as the acceleration of gravity, and

$\varrho$ as the fluid density, a constant.

Then the equations of horizontal motion are

$$
\left.\begin{array}{l}
\frac{D u}{D t}-f v=-\frac{1}{\varrho} \frac{\partial p}{\partial x} \\
\frac{D v}{D t}+f u=-\frac{1}{\varrho} \frac{\partial p}{\partial y}
\end{array}\right\}
$$

Cross-differentiation and subtraction of equations (1) yield the primitive vorticity equation

$$
\frac{D(\zeta+f)}{D t}=-(\zeta+f)\left[\frac{\partial u}{\partial x}+\frac{\partial v}{\partial y}\right]+\left[\frac{\partial w}{\partial y} \frac{\partial u}{\partial z}-\frac{\partial w}{\partial x} \frac{\partial v}{\partial z}\right]
$$

where $\zeta=\frac{\partial v}{\partial x}-\frac{\partial u}{\partial y}$, the vertical component of relative vorticity. Under the stated conditions, $u$ and $v$ are independent of $z$ and the last term in (2) is identically zero. By substitution of the incompressible continuity equation

$$
\frac{\partial u}{\partial x}+\frac{\partial v}{\partial y}=-\frac{1}{h+\eta} \frac{D(h+\eta)}{D t}
$$

(where $\eta$ is the height of the free surface above a level surface, and $\dot{h}(x, y)$ is the depth); equation (2) becomes

$$
\frac{D}{D t} \frac{(\zeta+f)}{(h+\eta)}=0
$$

where $\eta$ is usually negligible compared to $h$. This equation expresses the conservation of potential vorticity along a trajectory.

Several features of the barotropic flow are readily apparent from equation (3). In the absence of relative vorticity, the flow is along contours of $f / h$. These are zonal over a flat bottom, and at high latitudes they approach the isobaths. If an initially uniform zonal flow 
enters a region of increased or decreased depth, the changes in $\zeta$ and $f$ required by equation (3) permit a downstream oscillation for eastward flow, but not for westward flow.

If the flow is steady, a volume transport streamfunction can be defined by

$$
\frac{\partial \psi}{\partial y}=-u(h+\eta), \frac{\partial \psi}{\partial x}=v(h+\eta) \text {. }
$$

In terms of the streamfunction, the vorticity equation becomes

$$
\frac{D}{D t}\left[\frac{\nabla \cdot\left(\frac{1}{h} \nabla \psi\right)+f}{h}\right]=0
$$

The retention of this equation in Lagrangian form is advantageous in that it avoids the nonlinearity associated with the Eulerian form. The first integral of equation (4) is

$$
\frac{\nabla \cdot\left(\frac{1}{h} \nabla \psi\right)+f}{h}=\text { a constant along a streamline in steady flow. }
$$

Solution for zonal flow. A solution to equation (5) may be readily found when both the bathymetric relief and the variable Coriolis parameter can be expressed in terms of the initial flow pattern. This is accomplished by taking the bathymetry to be independent of $y$ and the upstream flow to be zonal and irrotational. Specifically, at some point upstream of the region of interest, say at $x=x_{0}$, the flow is defined by $\psi=-U H y$, where $H$ is a constant depth and $U$ is the velocity. For $x>x_{0}$, the depth is a function of $x$ only, $h(x)$. In the beta-plane approximation, with the $x$-axis along the equator, the Coriolis parameter is $f=\beta y$. Thus in the upstream region, $\psi=-U H y$ and $f(\psi)=\beta y(\psi)=-\beta \psi / U H$. Therefore, for $x>x_{0}$, equation (5) becomes

$$
h \nabla^{2} \psi-\frac{d h}{d x} \frac{\partial \psi}{\partial x}+\frac{\beta h^{3}}{U H^{2}} \psi=-h^{2} \beta y .
$$

At $x=x_{0}$, the relevant matching conditions are that the transport components are continuous, namely,

$$
\left.\begin{array}{l}
\frac{\partial \psi}{\partial x}=0 \\
\frac{\partial \psi}{\partial y}=-U H
\end{array}\right\} .
$$

Equation (6) may be separated and put into more tractable form through the use of the transformations

Equation (6) then becomes

$$
\psi(x, y)=y G(s) ; s=\frac{p}{H} \int_{x_{0}}^{x} h(x) d x ; D(s)=-\frac{h(x)}{U H^{2}} ; p^{2}=\frac{\beta}{U} .
$$

subject to the conditions

$$
G^{\prime \prime}+G=\frac{1}{D(s)}
$$

$$
\left.\begin{array}{l}
G(0)=-U H \\
G^{\prime}(0)=0
\end{array}\right\}
$$

The solution of (9) subject to (10) is

$$
G(s)=-U H \cos s+\int_{0}^{s} \frac{\sin (s-t)}{D(t)} d t .
$$


Solution (11) may be evaluated, if only numerically, for any flow regime that satisfies the following summarized assumptions:

1. The ocean (or atmosphere) may be idealized as homogeneous with a free upper surface.

2. The influence of friction is negligible.

3. The convergence of the meridians may be neglected, and the meridional variation of the Coriolis parameter may be approximated as a linear function of the distance from the equator (beta-plane approximation).

4. Displacements of the free surface are small compared to the total height of the fluid column.

5. The initial flow is zonal with zero relative vorticity.

6. The depth varies only with longitude.

7. The flow is stationary.

Evaluation of simple profiles. The solution is valid for easterly or westerly flow in either hemisphere. The variable $s$ is real for flow to the east and imaginary for flow to the west. As the wave-like disturbances in easterly currents are of primary interest, consideration is henceforth restricted to this type of flow. Although the exponential nature of the solution for westerly currents is of some interest, the finite meridional extent of natural bottom features can be expected to alter seriously the flow under these conditions.

Two basic bathymetric forms are readily incorporated into solution (11). The simpler form is a discontinuous change of depth between two regions of uniform depth. The flow over such a step may be matched with flow over further downstream steps to model any desired degree of bathymetric complexity. For two successive steps (either up, down, or of opposite sign) the downstream flow is given by

$$
\begin{aligned}
\psi=\frac{-U H y}{r_{3}}[ & {\left[1+\left(1-r_{2}\right) \sin r_{2} p a \sin r_{3} p(x-a)-\right.} \\
& \left.-\left\{\left(1-r_{2}\right) \cos r_{2} p a+\left(\frac{r_{2}}{r_{3}}-1\right)\right\} \cos r_{3} p(x-a)\right],
\end{aligned}
$$

where $a$ is the width of the intermediate region, $r_{2}$ is the ratio of the intermediate and initial depths, and $r_{3}$ is the ratio of the final and initial depths. The flow over the intermediate region is obtained by setting $r_{3}=r_{2}$ in solution (12).

It is apparent that the bracketed term in (12) will vanish for certain values of $r_{2}$ and $a$. Such an instability arises for the case of a single step when $r_{2} \geq 2$. For the case $r_{3}=1$, the flow occurring downstream from a plateau or valley is unstable if

$$
\left(1-\cos r_{2} p a\right)^{2}+r_{2}^{2} \sin ^{2} r_{2} p a \geq\left[\frac{r_{2}}{1-r_{2}}\right]^{2} \text {. }
$$

A rough calculation shows the downstream flow to be stable for all $a$ if $0.7<r_{2}<2$. As was noted above, if $r_{2}>2$, the flow in the intermediate region tends towards instability.

The features of solution (12) are best illustrated by inverting (12) and plotting the normalized streamline, $\frac{-U H y}{\psi}$, against $x$. The two parts of Fig. 1 show the results for a single step: Fig. 1a, the stable case of $h=0.5 H$; and Fig. $1 \mathrm{~b}$, the unstable case of $h=2.5 H$. In the latter example the streamlines show a cellular structure that extends to infinity at periodic values of $x$. Fig. 2 shows a more complex case of stable flow over a plateau whose width is $1 / 6$ wavelength. Fig. 3 shows the instability that arises when the width of a plateau is $1 / 2$ wavelength. When the width of a plateau is exactly 1 wavelength, the sudden increase in depth exactly balances the relative vorticity, and the downstream flow proceeds undisturbed at the original latitude, as shown in Fig. 4. Large amplitude stable waves that may be caused by flow over a valley are shown in Fig. 5 . 
A second bathymetric form, representing a sloping transition region between two regions of constant depth, can be used to investigate whether or not the flow features described above are caused by the unrealistic discontinuous change in depth. Such a transition region is given by the expression $h(x)=H x_{0} / x$, which, when substituted into equations (8) and (11) yields

$$
\dot{\psi}=\frac{-U H y p x_{0}}{1+p^{2} x_{0}{ }^{2}}\left[p x+\frac{\cos \left(p x_{0} \ln x / x_{0}\right)}{p x_{0}}-\sin \left(p x_{0} \ln x / x_{0}\right)\right] .
$$

Values of $x$ and $x_{0}$ may be chosen to give any desired slope. Fig. 6 shows solution (13).matched to solution (12), such that the final depth is 0.4 of the initial depth and is attained over a distance on the order of $100 \mathrm{~km}$. Also shown in Fig. 6 is the solution for a discontinuous decrease in depth of the same amount (dashed line). It is clear that in this example the main effect of a sloping transition region is a phase shift in the downstream flow pattern.

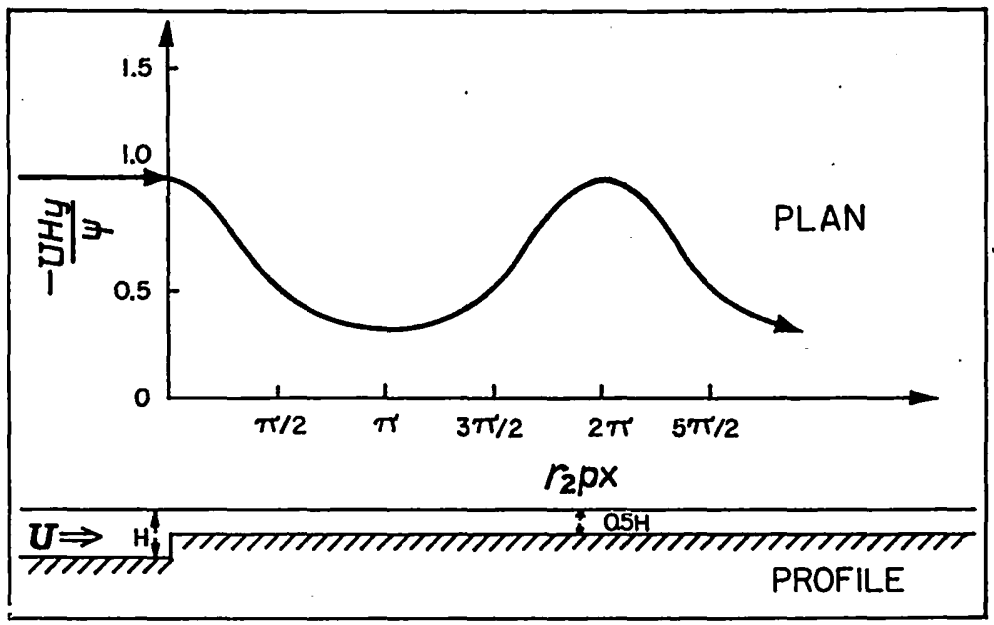

Fig. 1a. Zonal flow over a shoaling step

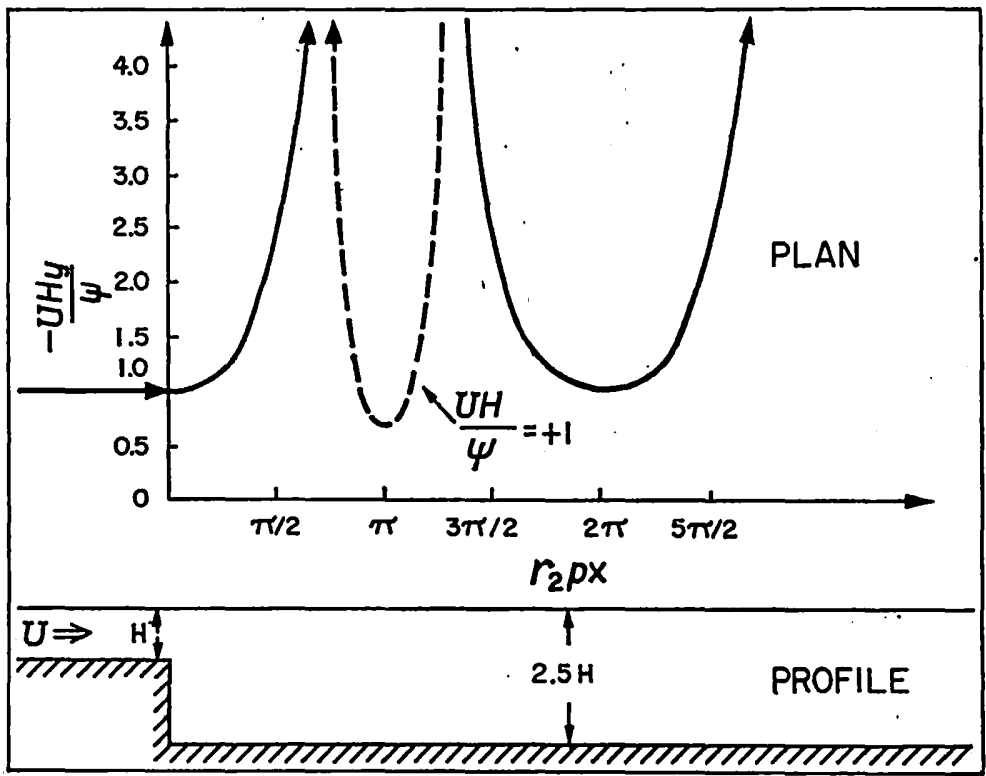

Fig. 1b. Zonal flow over a deepening step 


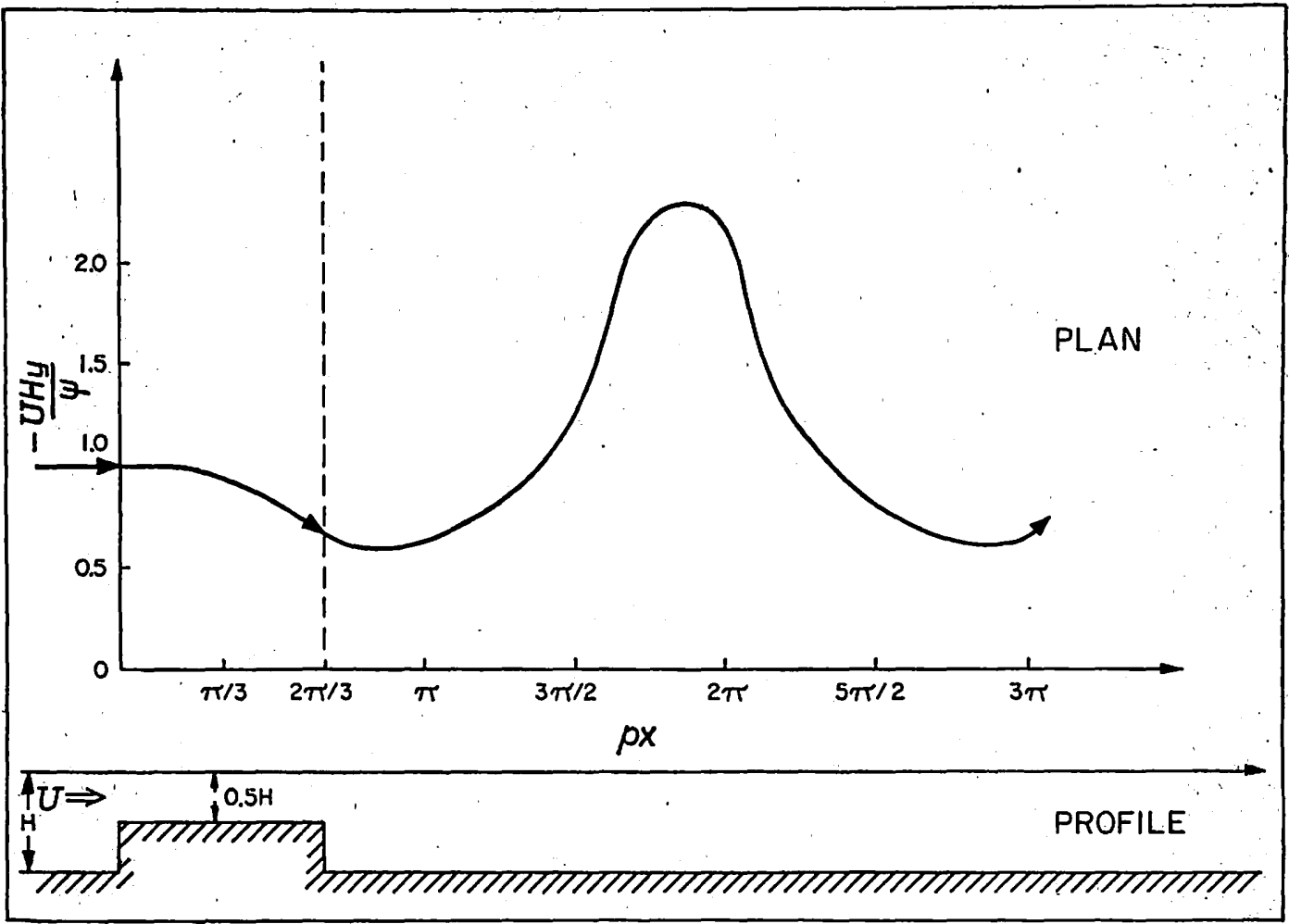

Fig. 2. Zonal flow over a narrow plateau

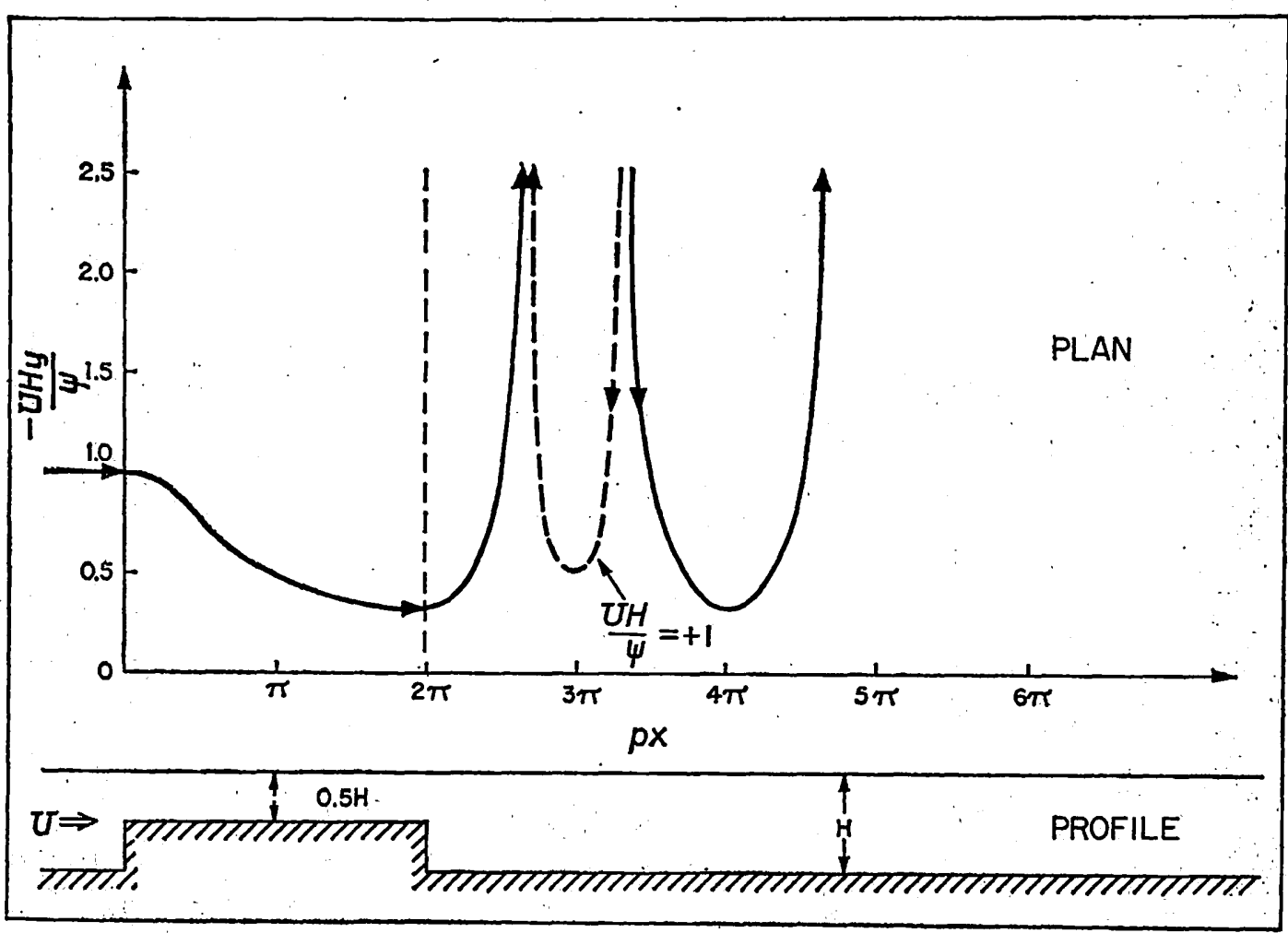

Fig. 3. Unstable zonal flow over a plateau 
Porter, Rattray, Jr., Influence of Variable Depth on Steady Zonal Barotropic Flow 171

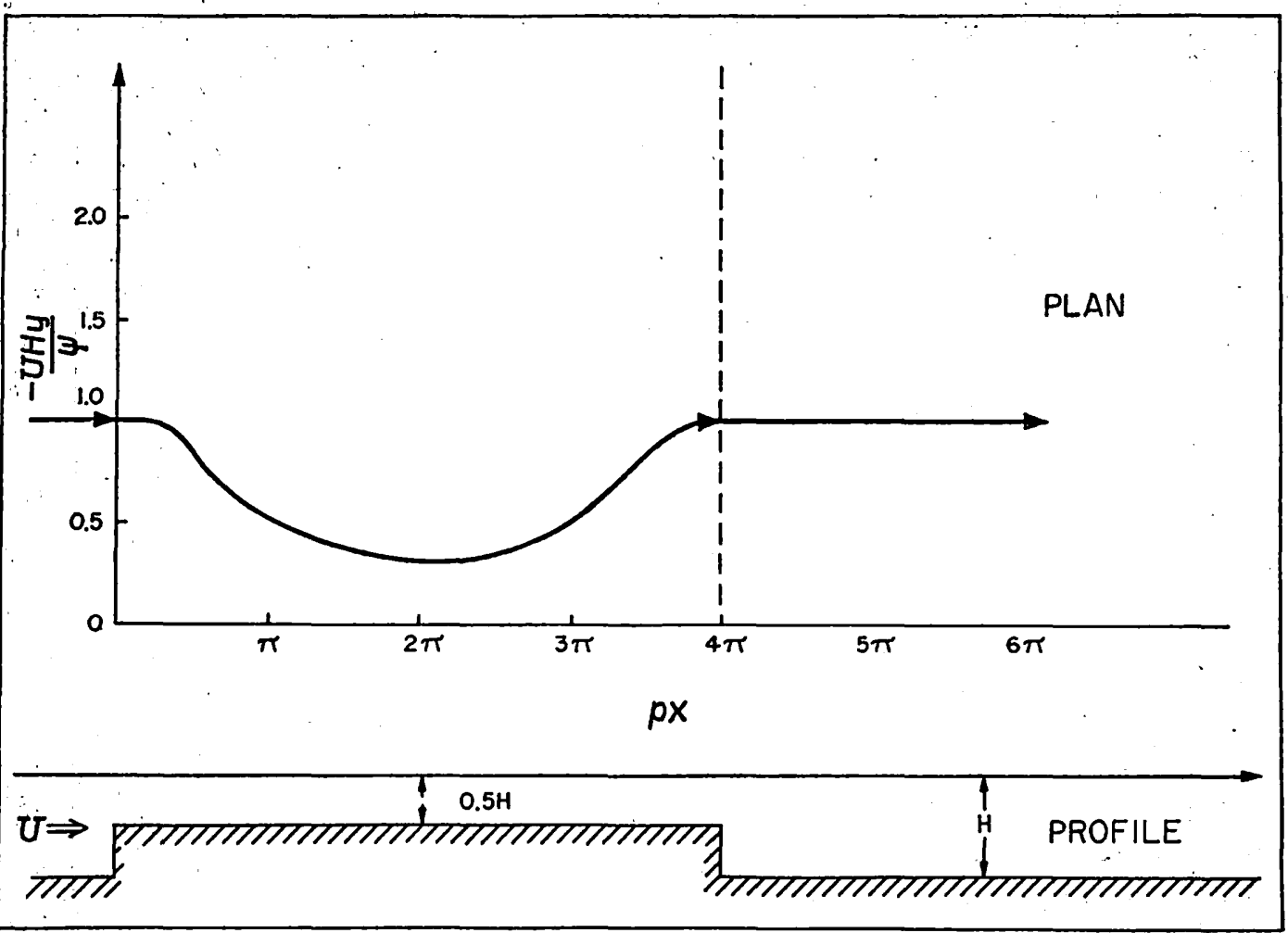

Fig. 4. Zonal flow over a plateau

s. is

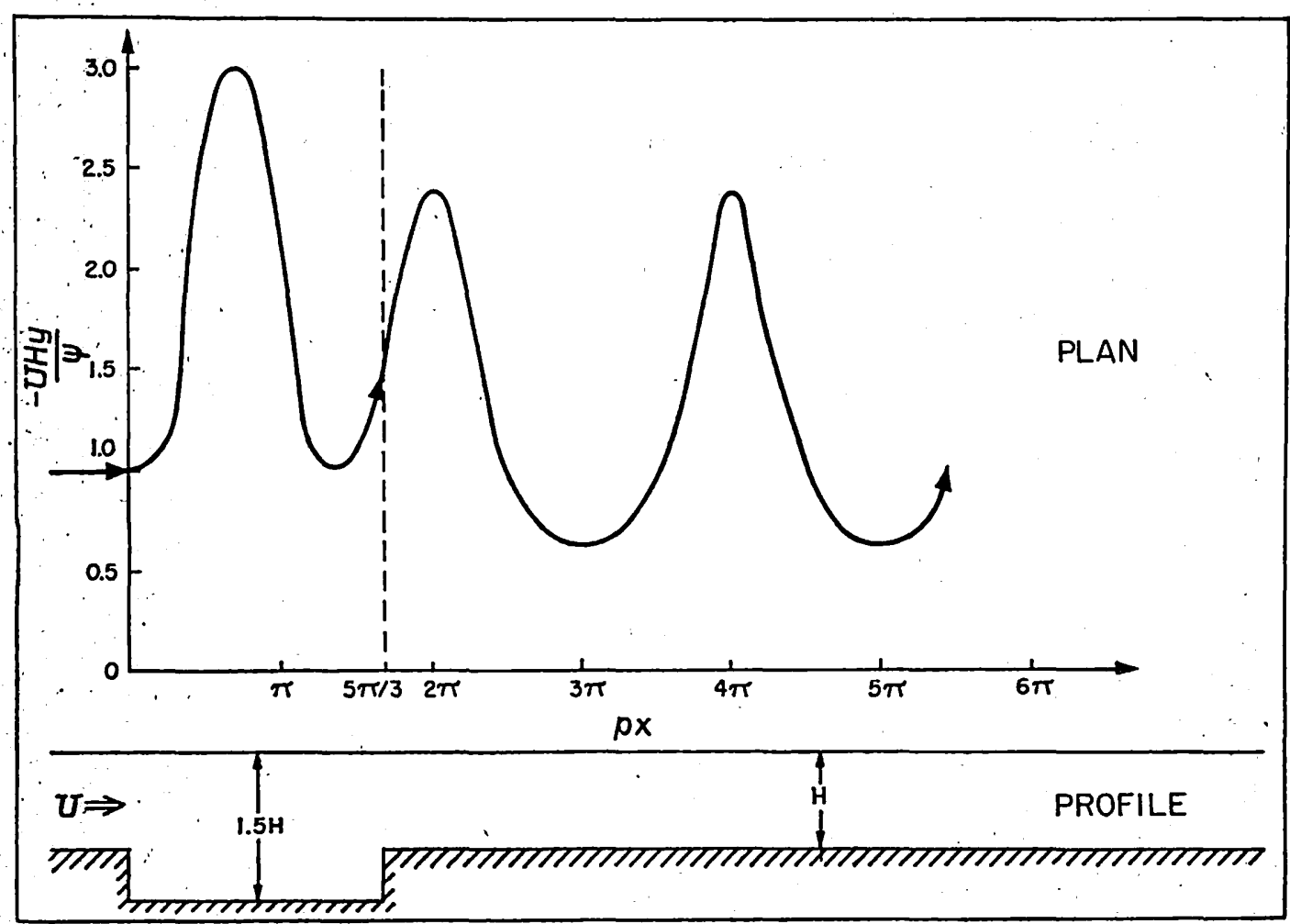

Fig. 5. Zonal flow over a flat-bottomed valley 


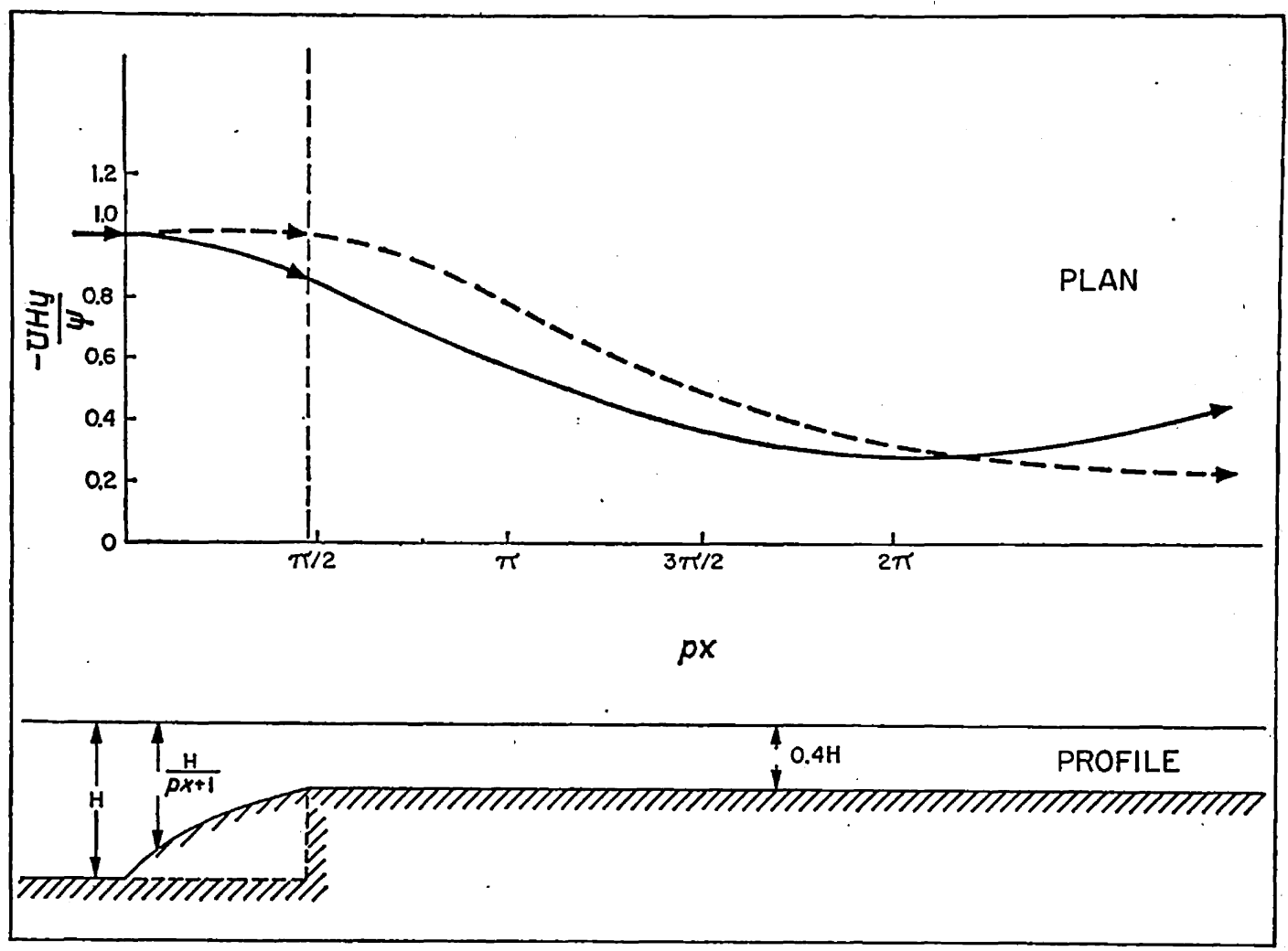

Fig. 6. Zonal flow over a transition slope

Discussion. For many conditions of barotropic flow, these investigations show that a stationary Rossby-wave pattern will form downstream from a ridge or valley. This important effect can result in the modification of streamlines by bathymetric features which occur at some distance upstream and which might otherwise be overlooked as the cause for the streamline pattern.

Since the essential mechanism operates equally well in baroclinic flow, similar behavior can be expected for this case. Apparent differences will arise largely out of the vertical variation in the velocity. One might expect that some form of "average" or effective velocity determines the wavelength required for stationarity of the wave pattern, while the amplitude of the waves will be governed by the velocity near the bottom. The latter velocity is generally a small fraction of the effective velocity and the amplitude of the resulting waves is correspondingly reduced. This feature may be incorporated into the above theory by using a reduced or effective depth scale for the bottom relief, such as suggested by B. Saint-Guily [1962]. However, it is not clear what the combined effect might be for the case where both baroclinic and barotropic flows occur. Data for the effects of bathymetry on baroclinic flow are available: in the literature and it is of some interest to see how they compare with the theoretical results when modified as indicated above.

Two examples with fairly simple isolated bathymetric features can be seen (Fig. 7) in the flows over the New Zealand Plateau $\left(50^{\circ} \mathrm{S}-165^{\circ} \mathrm{E}\right)$ and over the Kerguelen-Gaussberg Ridge: $\left(55^{\circ} \mathrm{S}-75^{\circ} \mathrm{E}\right)$. In both cases the conditions are similar to those represented in Fig. 4, in that there is no downstream oscillation. The amplitude of about 10 degrees of latitude and wave-j length of about $780 \mathrm{~km}$ observed over the Neri Zealand Plateau correspond to an effective velocity of $25 \mathrm{~cm} \mathrm{~s}^{-1}$ and a value of 0.9 for the ratio of effective depth of: the plateau to surrounding depth. The actual depth ratio is 0.4 . For the Kerguelen-Gaussberg Ridge, 


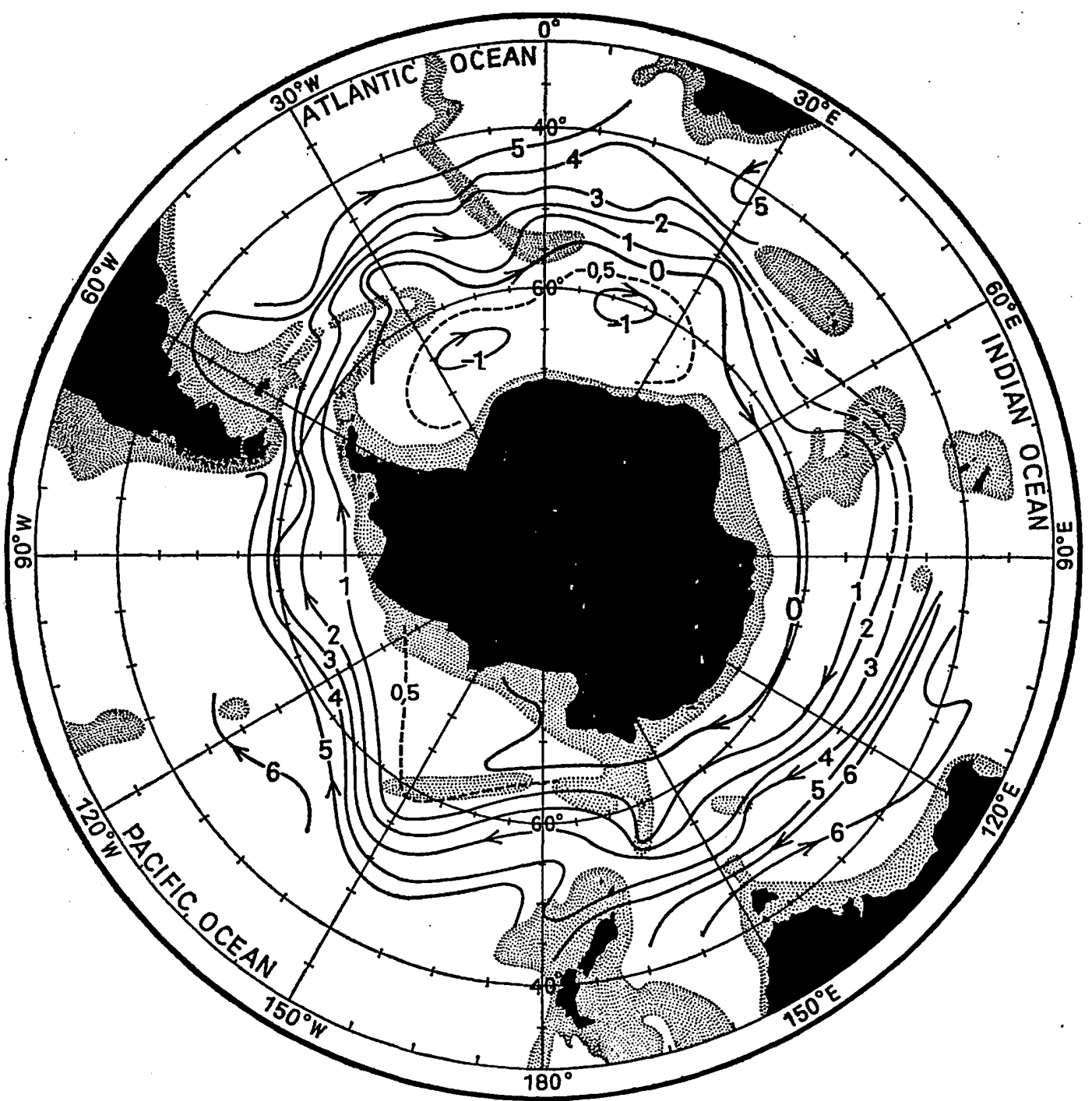

Fig. 7. Transport lines around the Antarctic Continent (H. U. Sverdrup, M. W. Johnson, R. H. Fleming [1942]

with an amplitude of 7-8 degrees and a wavelength of $550 \mathrm{~km}$, the effective velocity is $10 \mathrm{~cm} \mathrm{~s}^{-1}$ and the effective depth ratio is 0.94 , compared to the actual ratio of 0.8 . The fact that one finds reasonable values for these flow conditions indicates that the behavior of baroclinic flow in regions of varying bathymetry can be understood in terms of the results found above for barotropic flow.

The effect of bathymetry in forming standing wave patterns in an ocean current is shown to be much more complicated than previously had been thought. Further investigations are desirable in order to extend the above theory to include more realistic and complex conditions.

\section{Referonces}

Ekman, V. W., 1923: Ǔber Horizontalzirkulation bei winderzeugten Meeresströmungen. Ark. Math., Astr. och Fys. 17 (26), 1.
Ekman, V. W., 1932: Studion zur Dynamik der Meeresströmungen. Gerlands Beitr. z. Geophys. 36, 385. 
Fuglister, F.C., 1963: Gulf Stream. Trans. Am. Geophys. Union, 44 (2), 498.

Gambo, K., 1957: The scale of atmospheric motions and effect of topography on numerical weather prediction in the lower atmosphere. Pap. Met. Geophys., Tokyo, 8, 1.

Görtler, H., 1941: Einfluß der Bodentopographie auf Strómungen über der rotierenden Erde. Z. Angew. Math. Mech. 21 (5), 279.

Neumann, G., 1960: On the effect of bottom topography on ocean currents. Dt. Hydrogr. Z. 132.

Oi,M., 1956: Topographic perturbation of a zonal current. Meteorol. Notes Met. Res. Inst., Kyoto Univ., Series 2, No. 10, 16.

Saint-Guily, B., 1962: On the general form of the Ekman Problem. Proc. Symp. Math.-Hydrodynamical Methods Phys. Oce- anogr. Sept. 1961. Inst. Meereskde. Univ. Hamburg, 61 .

Shtokman, V.B., 1948: Effect of bottom topography on the direction of the transport of water set up by wind or the mass field in a nonhomogeneous ocean. Dokl. Akad. Nauk SSSR, 59 (5), 889. (English transl. by E. R. Hope in Defence Res. Bd. Canada, T 67 R, 20 pp., 1952).

Sverdrup, H. U., 1941: The influences of bottom topography on ocean currents. Appl. Mechanics, Th. v. Kármán Anniv. Vol., 66.

Sverdrup, H. U., M. W. Johnson, and R. H. Fleming, 1942 : The Oceans, p. 468. Prentice-Hall, New York.

Warren, B., 1963: Topographic influences on the path of the Gulf Stream. Tellus, 15 (2), 167.

Eingegangen im April 1964 